\title{
1 Soil microbiome drives the recovery of ecosystem functions after fire
}

2 Pérez-Valera $\mathrm{E}^{1,2^{*}}$, Verdú $\mathrm{M}^{1}$, Navarro-Cano $\mathrm{JA}^{1}$, Goberna $\mathrm{M}^{3}$

3

$4{ }^{1}$ Department of Plant Ecology, Centro de Investigaciones sobre Desertificación (CSIC-

5 UVEG-GV), Carretera Moncada - Náquera, km 4.5, Moncada, Valencia 46113, Spain

$6 \quad{ }^{2}$ Biology Centre of the Czech Academy of Sciences, Institute of Soil Biology, Na

$7 \quad$ Sádkách 702/7, 37005 České Budějovice, Czech Republic

$8 \quad{ }^{3}$ Department of Environment and Agronomy, Instituto Nacional de Investigación y

9 Tecnología Agraria y Alimentaria (INIA), Ctra. de la Coruña, km 7.5 - 28040 Madrid,

10 Spain

11

12 *Corresponding author: Eduardo Pérez-Valera (eduardo.perez.valera@ upb.cas.cz) 


\section{Abstract}

Fire is an ecological disturbance that alters soil microbiomes and the functions they mediate in terrestrial ecosystems. Soil microbial diversity in Mediterranean Basin ecosystems shows resilience to fire following the restoration of plant-soil feedbacks.

We hypothesised that microbial functions related to organic matter decomposition and nutrient cycling might show similar patterns of recovery. We quantified the rates of microbial respiration and enzymatic activities related to $\mathrm{C}, \mathrm{N}$ and $\mathrm{P}$ cycling in three 20year fire chronosequences including 150 transects in 50 burned and unburned plots (no historical fire registers) in a paired experimental design. Microbial functions, except for the hydrolysis of $\mathrm{N}$ compounds, were sensitive to fire but recovered the levels of unburned plots in approximately 20-24 years. The recovery of microbial functions responded to abiotic and biotic drivers. Total soil nitrogen concentration was overall strong predictor of microbial functions. In addition, fungal phylogenetic diversity significantly explained the post-fire trajectories of potentially mineralizable $\mathrm{C}$, while bacterial diversity was involved in the restoration of organic $\mathrm{C}$ and $\mathrm{P}$ hydrolysis. Our results suggest that the long-term recovery of soil biodiversity in Mediterranean Basin ecosystems creates resilience to restore essential ecosystem functions after fire.

\section{Keywords} bacteria, decomposition, fungi, Mediterranean soils, nutrient cycles, phylogenetic diversity 


\section{Introduction}

Fires are widespread ecological disturbances that cause drastic changes in plant communities, modify the soil physical and chemical environment and ultimately alter soil microbiomes (Certini, 2005; Keeley et al., 2012). Combustion of organic matter and denaturation of enzymes caused by elevated temperature during fire directly impact microbially-mediated ecosystem functions (hereafter 'EFs'), including the decomposition of organic matter and the transformation of essential compounds related to carbon, phosphorous and nitrogen cycling (Certini, 2005; Knicker, 2007; LópezPoma and Bautista, 2014). In parallel, shifts in the diversity and composition of soil microbiota can exert immediate changes in microbial EFs (Hart et al., 2005; BárcenasMoreno et al., 2011; Goberna et al., 2012; Graham et al., 2016).

\section{In Mediterranean Basin ecosystems, where biological communities have co-existed} with fire over evolutionary timescales, plants show high resilience to frequent fire (Lavorel 1999; Keeley et al., 2012). Major groups of soil microbes show different levels of resistance - i.e. the degree to which microbial composition remains unchanged in the face of a disturbance - and resilience - i.e. the rate at which microbial composition returns to its original composition after being disturbed (Allison and Martiny, 2008; Griffiths and Philippot, 2013). Archaeal communities are the most resistant to high temperatures due to various heat-protection mechanisms such as ether (rather than ester) lipid membrane and DNA stabilization mechanisms (i.e. higher GC ratio) (Stetter, 1999). The extent of resistance and resilience of archaeal communities seem time- and context-dependent, as few available studies report from no fire-induced changes in community composition up to shifts that are not recovered after two years (Goberna et al., 2012; Mikita-Barbato et al., 2015; Pérez-Valera et al., 2018). Bacterial and fungal 
communities are more sensitive to fire, and show changes in community composition as well as reduced richness (Hart et al., 2005; Dove and Hart, 2017; Castaño et al., 2020; Sáenz de Miera et al., 2020). Soil bacteria are thought to be less sensitive than fungi to fire-induced changes in terms of biomass, richness and diversity (Pressler et al., 2019). Counterintuitively, richness reduction in both soil fungi and bacteria comes at increased levels of phylogenetic diversity (Rincón et al., 2014; Pérez-Valera et al., 2018).

Opposing trends in taxonomic and phylogenetic diversity indicate that microbial communities after fire contain less taxa which are evolutionarily more distantly related. Plant recovery over time enriches the soil with organic matter (Johnson and Curtis, 2001), eventually restoring the naturally low levels of bacterial and fungal phylogenetic diversity (Fig. S1; Pérez-Valera et al., 2018). Drop of phylogenetic diversity during microbial community reassembly can result from the recovery of competitive hierarchies between deeply-branching lineages that operate under carbon-rich conditions (Goberna et al., 2014). Whether such a long-term restoration of soil microbial diversity drives the recovery of microbial EFs remains to be elucidated.

Based on the multi-level resilience of Mediterranean Basin ecosystems to fire, and on the observation that main biological groups shaping the soil microbiome are recovered within approximately two decades (Fig. S1; Pérez-Valera et al., 2018), we hypothesised that microbial EFs might undergo a similar recovery rate. To test our hypothesis, we studied three 20-year fire chronosequences, i.e. a set of ecologically similar sites that differ in their time since fire, including 150 transects across 25 burned plots and their 25 unburned counterparts. We quantified the $\mathrm{C}$ mineralization potential and enzymatic activities involved in nutrient cycling. Then, we evaluated the fire-induced shifts in microbial EFs and linked them to changes in soil abiotic properties and the relative 
abundance of main fungal and bacterial lineages. We did not consider archaeal communities, since we previously described that archaeal diversity and community composition did not respond to fire in our study sites (Pérez-Valera et al., 2018).

Finally, we sought whether the recovery of each EF responds to abiotic (soil properties)

or biotic drivers (fungal and bacterial diversity). To do so, we used phylogenetic diversity since, by incorporating the evolutionary relationships between lineages, these metrics are able to capture shared functional abilities and are thus better proxies of microbial EFs (Martiny et al., 2015; Goberna and Verdú, 2016, 2018).

\section{Material and Methods}

\subsection{Study area and experimental design}

We designed a space-for-time substitution experiment, in which we characterised three fire chronosequences in the north, centre and south of Valencia (E Spain). Each chronosequence contained eight to nine sites that had experienced a single wildfire event between 1994 and 2014 according to the historical fire registers provided by the Regional Government (Pérez-Valera et al., 2018). Based on the climatic conditions in the study area, ignition date (mostly in the hot and dry season) and fuel availability in unburned nearby sites, it can be assumed that fires were generally of high intensity. Chronosequences were located at (mean \pm SE) $84 \pm 22 \mathrm{~km}$ between each other, estimated as the pairwise mean distance between chronosequence centroids (i.e. the middle geographical point across sites). Within each chronosequence, sites were respectively located on average at $11.5 \pm 0.8,10.2 \pm 1.2$, and $10.8 \pm 1.8 \mathrm{~km}$ between each other. Environmental heterogeneity across sites was reduced by selectively looking for areas that fulfilled similar criteria of land-use (forest soil), lithology (calcareous), slope orientation ( $\mathrm{N}$ to $\mathrm{E}$ ) and steepness $\left(15 \pm 1^{\circ}\right)$, as well as plant cover by using GIS with 
112 local maps and ortophotographs. Plant communities were generally consisted of evergreen shrublands with Pinus halepensis and varying abundance of Quercus coccifera, Rosmarinus officinalis, Ulex parviflorus and Cistus species. Site features were further validated in situ during an extensive field inspection. All details and UTM site locations can be found in Pérez-Valera et al. (2018).

To further account for environmental heterogeneity, we established a paired experimental design, each site having a burned and an unburned plot, according to historical fire registers (comprising up to 38 years before sampling; Table S1 in PérezValera et al., 2018). In unburned plots we detected no signs of burning in the vegetation or soil profile during field inspections either. Paired burned and unburned plots $(30 \times 30$ m each) had similar environmental conditions, land-use history and were located as close as possible but avoiding the fire edge (on average $435 \pm 49 \mathrm{~m}$ separation). (total organic $\mathrm{C}$, total $\mathrm{N}, \mathrm{pH}$, humidity, electrical conductivity and $\mathrm{NO}_{3}{ }^{-}-\mathrm{N}$ contents) showed spatial autocorrelation at short distances $(<10 \mathrm{~km})$, according to Mantel matrices (see Fig. S4 in Pérez-Valera et al., 2018). In addition, total inorganic carbon, which is not expected to be affected by fire unless temperature exceeds $1000{ }^{\circ} \mathrm{C}$ (Certini, 2005), did not differ significantly between paired plots.

\subsection{Soil sampling and sample analysis}

Soil samples were taken at 0-5 cm depth over a 5-day period in May 2014. Three linear apart, making a total of 150 samples ( 25 sites $\times 2$ plots $\times 3$ transects). Prior to sample 
collection, the ash layer, litter, mosses and stones were removed if present. Along each transect, ten subsamples (ca. $100 \mathrm{~g}$ each) were regularly taken every $2.5 \mathrm{~m}$ and pooled into one composite sample per transect. Soil samples were transported to the laboratory in an icebox containing cooling blocks, sieved through a $2 \mathrm{~mm}$ mesh upon arrival to the laboratory and kept at $5{ }^{\circ} \mathrm{C}$ during subsequent analyses. Soil physical and chemical properties, including $\mathrm{pH}$, water content, electrical conductivity, total organic $\mathrm{C}$, total $\mathrm{N}$, ammonium $\left(\mathrm{NH}_{4}{ }^{+}-\mathrm{N}\right)$ and nitrate $\left(\mathrm{NO}_{3}{ }^{-} \mathrm{N}\right)$, were analysed following standard procedures, as described and published in Pérez-Valera et al. (2018).

\subsection{Microbial respiration and enzymatic activities}

147 We measured microbial heterotrophic respiration under optimal conditions in root-free sieved soil samples, and used it as an indicator of $\mathrm{C}$ mineralization potential (Nannipieri et al., 1990). $\mathrm{CO}_{2}-\mathrm{C}$ production was measured during an aerobic incubation in the dark (60\% water-holding capacity, $28^{\circ} \mathrm{C}, 30$ days) using a 6700 Headspace $\mathrm{CO}_{2}$-analyzer (Illinois Instruments) as in Pérez-Valera et al. (2019). We fitted the curve of $\mathrm{CO}_{2}-\mathrm{C}$ production over time to a density-dependent logistic growth equation:

$$
\mathrm{CO}_{2}-\mathrm{C}=\frac{\mathrm{CO}_{2}-C_{\max }}{1+e^{-r(t-s)}}
$$

, where $\mathrm{CO}_{2}-\mathrm{C}_{\max }$ indicates the asymptote or maximum degree of $\mathrm{CO}_{2}-\mathrm{C}$ production, $r$ the exponential rate of $\mathrm{CO}_{2}-\mathrm{C}$ production, $t$ the time at which $\mathrm{CO}_{2}-\mathrm{C}$ production was quantified and $s$ the time at the midpoint of the exponential portion of the curve. We estimated the kinetic parameters of $\mathrm{C}$ mineralization potential in $\mathrm{R}$ 3.6.0 (R Core Team, 2019). $\mathrm{CO}_{2}-\mathrm{C}_{\max }$ was the most responsive to fire and used for further analyses (details below). 
Enzymatic activities related to $\mathrm{C}$ ( $\beta$-glucosidase), $\mathrm{P}$ (alkaline phosphatase) and $\mathrm{N}$ (urease) cycling were quantified using standard procedures. Briefly, $\beta$-glucosidase and alkaline phosphatase activities were measured as the amount of p-nitrophenol (PNP) that $0.5 \mathrm{~g}$ of soil produced under controlled conditions of temperature $\left(37^{\circ} \mathrm{C}, 1 \mathrm{~h}\right)$ and pH (6 and 11, respectively) (Tabatabai and Bremner, 1969; Eiviazi and Tabatabai, 1988). Soil urease was quantified as the $\mathrm{NH}_{4}{ }^{+}-\mathrm{N}$ produced by $1 \mathrm{~g}$ soil after incubation for $2 \mathrm{~h}$ at $37^{\circ} \mathrm{C}$ and $\mathrm{pH} 10$ (Kandeler and Gerber, 1988).

\subsection{Microbial composition and phylogeny reconstruction}

172 We characterised the soil microbiome by extracting soil DNA and sequencing amplicons of fungal ITS regions and 16S rRNA genes (see Pérez-Valera et al., 2018 for a detailed description). Briefly, DNA was extracted in duplicates from ca. $0.25 \mathrm{~g}$ soil with the PowerSoil DNA Isolation Kit (MO BIO Laboratories, Carlsbad, CA, USA). DNA amplicons based on ITS1F and ITS4R primers for fungi (Gardes and Bruns 1993; White et al., 1990) and 515F and 806R primers for bacteria (Caporaso et al., 2012) were sequenced using Roche 454 FLX titanium instruments and reagents. After initial sequence processing (removal of sequences $<150 \mathrm{bp}$, including Ns or homopolymers $>6$ pb), we obtained 1,080,311 (7,202 \pm 269 per sample) fungal and 1,280,728 (8,538 \pm 278$)$ bacterial sequences. DNA sequences were clustered at a similarity of 97\%, producing 6,620 fungal and 7,003 bacterial Operational Taxonomic Units (OTUs) in Qiime 1.9.1 (Caporaso et al., 2010a) after discarding singletons. DNA sequencing showed Good's coverage of $0.97 \pm 0.001$ for fungi and $0.90 \pm 0.006$ for bacteria as calculated with the 
fractions per transect and corrected by the estimated number of 16S rRNA gene copies for bacteria (Kembel et al., 2012).

Fungal phylogenies were reconstructed by grafting OTUs into a genus-level tree that we constructed based on the literature. Bacterial phylogenies where reconstructed using RAxML (Stamatakis, 2014) by using representative OTU sequences previously aligned with PyNAST (Caporaso et al., 2010b). Tree topology was constrained at the phylum level (class for Proteobacteria). Multiple phylogenies for fungi $(n=5)$ and bacteria $(n=5)$ were reconstructed to accommodate phylogenetic uncertainty. Standardized mean phylogenetic distance (stdMPD) was calculated as a metrics of phylogenetic $\alpha$ diversity in picante for $\mathrm{R}$ (Kembel et al., 2010). Further details about phylogeny reconstruction along with the phylogenetic trees used here can be found in Pérez-Valera et al. (2018).

\subsection{Statistical analysis}

We tested the existence of short-term effects of fire on microbial functions, by comparing each $\mathrm{EF}$ (i.e. maximum degree of $\mathrm{CO}_{2}-\mathrm{C}$ production, as well as $\beta$ glucosidase, alkaline phosphatase and urease activities) in plots that had burned 0-3 years before sampling and their unburned counterparts through paired t-tests in R.

$$
\text { To estimate the post-fire recovery of EFs, we used the difference }(\Delta) \text { between paired }
$$
burned and unburned transects as the dependent variable and time since fire as the fixed effect variable in Bayesian generalized linear mixed models (GLMM) with MCMCglmm for R (Hadfield, 2010). In all GLMMs we incorporated the geographic distance matrix between transects as a random variable to account for the non- 
independence of nearby transects as in Stone et al. (2011). Average recovery times were calculated by interpolation or extrapolation through the equation of the fitted model.

212

To visualise the effects of fire on soil abiotic properties, specific microbial lineages differentials $(\Delta)$ of soil properties (i.e. TOC, TN, humidity, $\mathrm{pH}$, electrical conductivity, $\mathrm{NO}_{3}{ }^{-}-\mathrm{N}$ and $\left.\mathrm{NH}_{4}{ }^{+}-\mathrm{N}\right)$, relative abundances of fungal and bacterial phyla and microbial EFs. The PCA was performed with the function prcomp in R with the scale argument.

Finally, we evaluated whether the recovery of microbial EFs was explained by the variation in soil abiotic properties and/or microbial phylogenetic diversity, through two consecutive Bayesian GLMMs. In the first model, we used each $\triangle \mathrm{EF}$ as a dependent variable and soil abiotic properties (i.e. $\Delta$ in TOC, $\mathrm{TN}$, humidity, $\mathrm{pH}$, electrical conductivity, $\mathrm{NO}_{3}{ }^{-}-\mathrm{N}$ and $\mathrm{NH}_{4}{ }^{+}-\mathrm{N}$ ) as fixed factors, including time since fire and the geographic distance matrix as random variables as above. The second model had the same structure, but used the phylogenetic diversity of fungi and bacteria $\left(\Delta_{\mathrm{std}} \mathrm{MPD}\right)$ as fixed factors.

\subsection{Accession numbers}

Raw DNA sequences are available at the European Nucleotide Archive website

(http://www.ebi.ac.uk/ena/data/view/PRJEB13469 and

http://www.ebi.ac.uk/ena/data/view/PRJEB13853), as originally published in Pérez-

Valera et al. (2018). 
237 Fire significantly decreased the maximum degree of microbial $\mathrm{CO}_{2}-\mathrm{C}$ production, which we used as an indicator of soil organic $\mathrm{C}$ mineralization potential (Fig. 1, Table 1). Other kinetic parameters describing microbial respiration curves did not respond to fire, as was the case of the exponential rate of $\mathrm{CO}_{2}-\mathrm{C}$ change $(r)$ or the time at the midpoint of the curve ( $s$, Fig. S2). Soil $\beta$-glucosidase and phosphatase activities significantly dropped after fire, while urease activity did not respond to the disturbance (Fig. 1, Table 1). Soil microbial $\mathrm{CO}_{2}-\mathrm{C}$ production in burned plots increased with time since fire, and achieved the levels of unburned plots in 246.5 months (Fig. 1, Table 1). Similar patterns were observed for $\beta$-glucosidase (264.3 months) and phosphatase activities (293 months, Table 1).

Fire-induced shifts in microbially-mediated soil EFs correlated to changes in soil abiotic properties and microbial relative abundances, as shown by the PCA containing paired burned and unburned differences $(\Delta)$ for each variable (Fig. 2). In the figure depicting the first two principal components (PCs), recently burned plots tend to be located in the upper left portion of the graph while plots burned long ago are in the bottom right area (Fig. 2). The effect of time since fire overrode the environmental heterogeneity encompassed in all three chronosequences in determining the distribution of our samples in the same biplot, which did not show any clear pattern (Fig. S3). In particular, the first PC ( $22.5 \%$ variance) correlated to parameters that responded to fire and recovered with time such as $\mathrm{pH}$ (negative pole), and humidity, TOC and TN (positive pole, Fig. 2). High values in $\Delta \mathrm{TOC}, \Delta \mathrm{TN}$ and $\Delta$ humidity, and low values in $\Delta \mathrm{pH}$ associated with the positive pole of PC1 indicating similar levels in burned and unburned plots (according to the exploration of raw data). Thus, this axis can be 
261 interpreted as the post-fire recovery of soil organic matter. Microbial lineages such as

262 Ascomycota and Firmicutes, among others, were favoured soon after fire, as shown by

263 their negative loadings in PC1, while the recovery mainly promoted Basidiomycota and

264 Glomeromycota (positive pole, Fig. 2; Figs. S4 and S5). The response of lineages such

265 as Proteobacteria, Actinobacteria and Chytridiomycota, which showed higher

266 dependence on changes in mineral $\mathrm{N}$ (i.e. $\mathrm{NH}_{4}{ }^{+}-\mathrm{N}$ and $\mathrm{NO}_{3}{ }^{-}-\mathrm{N}$ ) correlated with PC2

267 (12.7\% variance), had complex and class-dependent fire responses and post-fire

268 evolution (Fig. 2; Figs. S4, S5 and S6).

269

To analyse the drivers of the shifts in microbial EFs we performed statistical models that used as predictors soil abiotic properties and microbial phylogenetic diversity, as a means to account for the complexity of microbial responses. Both abiotic and biotic drivers explained the variation in all microbial EFs, except for urease activity that responded exclusively to abiotic factors. Recovery of total nitrogen was an overall predictor of microbial EFs, while restoration of the levels of $\mathrm{pH}, \mathrm{NO}_{3}{ }^{-} \mathrm{N}$ and electrical conductivity partly explained maximum $\mathrm{CO}_{2}-\mathrm{C}$ production and $\beta$-glucosidase activity (Table 2). Urease activity also responded to TOC and soil humidity. Importantly, our models showed that microbial phylogenetic diversity also explained the restoration of essential EFs. While fungal phylogenetic diversity was a good predictor of the trajectories of potentially mineralizable $\mathrm{C}$, bacterial diversity was involved in the restoration of the hydrolysis of organic $\mathrm{C}$ and $\mathrm{P}$ compounds (Table 2). In all cases, the lowest the levels of phylogenetic diversity, the highest the microbial EF rates (Table 2). 
287 Fire significantly decreased the $\mathrm{C}$ mineralization potential as well as the enzymatic hydrolysis of organic $\mathrm{C}$ and $\mathrm{P}$ compounds, while it did not alter that of $\mathrm{N}$ compounds. The decline in microbial activity, and particularly heterotrophic respiration and C- and P-related EFs in soils is a common observation following high-intensity fires (e.g. Fritze et al., 1993; Hernández et al., 1997; Bárcenas-Moreno et al., 2011; Uribe et al., 2013; Fernández-García et al., 2019). Such a decrease is due to the thermal denaturation of enzymes, drop in microbial biomass and altered microbial community composition (Knicker, 2007; Holden and Treseder, 2013; Fernández-García et al., 2019). However, these results differ from reported increases in microbial EFs following low to medium intensity burning (Bárcenas-Moreno and Bååth 2009; Goberna et al., 2012; PérezValera et al., 2019). Such enhancement might be caused by an incomplete combustion of organic matter that releases labile forms of $\mathrm{C}, \mathrm{N}$ and other macronutrients, and thus potentially induces microbial recolonization and activity in the short term (Certini 2014; Muñoz-Rojas et al., 2016). The lack of response of urease activity to fire adds complexity to reported decreases (Hernández et al., 1997; Goberna et al 2012; Fontúrbel et al 2012; Xue et al 2014; Pérez-Valera et al 2019) and increases (Ajwa et al., 1999) under post-burning scenarios. The observation that urease activity is unrelated to time since fire supports previous work in Mediterranean Basin ecosystems burned 3, 15 and 21 years ago (Moya et al., 2018). Contrasting results suggest that urease activity could be driven by differences in environmental (e.g. climatic, edaphic) conditions along with variations in fire severity (Moya et al., 2018, Fernández-García et al., 2018 and 2019) that determines the extent of urease inhibition owing to the pulse of ammonium-N that typically follows the combustion of organics (Hoare and Laidler, 1950). 
Rates of $\mathrm{C}$ mineralization potential in burned plots, as well as enzymatic hydrolysis of $\mathrm{C}$ and $\mathrm{P}$ compounds, increased with time since fire, and achieved the levels of unburned plots in 246.5-293 months. Altogether our results indicate that most of the studied functions were sensitive to fire, but resilient in a period of approximately 20-24 years. This observation is in line with previous reports indicating that soil microbial communities are generally sensitive to disturbance both in composition and function (Mataix-Solera et al., 2009), but can be resilient particularly to pulse (short-term intense) disturbance (Allison and Martiny, 2008; Shade et al., 2012). Resilience is seldom reported, probably due to bias in sampling intensity or duration (Shade et al., 2012). A review on 131 studies did not find evidence of recovery trends of microbial community composition within the first ten years after fire, although most studies monitored on average only the first two years (Pressler et al., 2019). A few experimental studies and meta-analyses support the recovery of microbial respiration and carbon cycling activities to pre-disturbance levels over periods ranging from ca. 3 to 15 years (Bárcenas-Moreno et al., 2011; Dooley and Treseder, 2012; López-Poma and Bautista, 2014; Yang et al., 2020). Our results in water-limited ecosystems suggest slower recovery EF rates. Differences across studies can originate from natural variation across biomes, as well as fire intensity and recurrence, which can significantly impact the response of soil microbial communities (Edigi et al., 2016; Pressler et al., 2019). We previously found that, in Mediterranean Basin ecosystems, the resilience to fire of plant communities is essential for the restoration of interrupted plant-soil feedbacks (PérezValera et al., 2018). It has been traditionally thought that the development of plant-soil feedbacks is extremely slow in drylands, but this idea has seldom been tested (NavarroCano et al., 2015). Our results suggest that, under dry conditions, litter inputs and improved resource availability in mineral soils during secondary succession may take at 
least two decades to effectively counteract the initial negative response. These results

are in line with previous reports on primary succession in nearby areas, where we described significant increments in soil fertility (e.g. six-fold rise in TOC) and microbial mediated functions during the first two decades after plant establishment (Navarro-Cano et al., 2015).

The recovery of microbial EFs responded both to abiotic and biotic drivers. The postfire trajectories of $\mathrm{C}$ mineralization potential, and rates of $\mathrm{C}, \mathrm{P}$ and $\mathrm{N}$ cycling showed complex linkages to soil abiotic properties as well as to the relative abundances of fungal and bacterial lineages. However, two main lessons can be extracted from our results. First, the recovery of total soil nitrogen was an overall predictor of microbial EFs, which fits well with the notion that nitrogen tends to be a limiting resource under Mediterranean conditions (Hooper and Johnson, 1999). Second, the recovery of soil microbial phylogenetic diversity underlay the restoration of essential EFs. Fungal phylogenetic diversity significantly explained the trajectories of $\mathrm{C}$ mineralization potential, while bacterial diversity was involved in the restoration of organic $\mathrm{C}$ and $\mathrm{P}$ hydrolysis. In all cases, the lowest the levels of phylogenetic diversity, the highest the microbial EF rates. We have previously reported high levels of microbial productivity at low levels of phylogenetic diversity (Pérez-Valera et al., 2015). Such a negative relationship might be mediated by the overrepresentation of a few lineages that are highly productive under carbon-enriched conditions, a pattern reported worldwide for soil bacteria (Goberna et al., 2014; Goberna and Verdú, 2018). In these 20-year fire chronosequences, the decrease with time since fire of microbial phylogenetic diversity mediated by the restoration of soil organic carbon (Pérez-Valera et al., 2018) underlies the recovery of $\mathrm{C}$ mineralization potential and nutrient cycling. 
In short, our results suggest that, in Mediterranean Basin ecosystems, the

relationship between soil microbial diversity and ecosystem functions is resilient to fire.

While efforts to date have largely addressed short-term effects of fires on soils, further research is needed to better understand their long-term consequences on the complex above-belowground linkages. Careful assessment of whether upcoming changes in the frequency and severity of fires disrupt the resilience of biological communities and the diversity-EF relationship is fundamental to ensure the preservation of diverse and sustainable fire-prone ecosystems.

\section{Acknowledgements}

Financial support was provided by the Spanish Ministry of Economy and

Competitiveness, and Generalitat Valenciana (grant numbers CGL2017-89751-R, BES-

Adán for field and laboratory work. We also thank the editors and three anonymous referees for valuable comments on the manuscript.

\section{References}

Ajwa, H.A., Dell, C.J., Rice, C.W., 1999. Changes in enzyme activities and microbial biomass of tallgrass prairie soil as related to burning and nitrogen fertilization. Soil

Allison, S.D., Martiny, J.B.H., 2008. Resistance, resilience, and redundancy in microbial communities. Proceedings of the National Academy of Sciences of the United States of America 105, 11512-11519. doi:10.1073/pnas.0801925105 
Bárcenas-Moreno, G., Bååth, E., 2009. Bacterial and fungal growth in soil heated at different temperatures to simulate a range of fire intensities. Soil Biology and Biochemistry 41, 2517-2526. doi:10.1016/j.soilbio.2009.09.010

Bárcenas-Moreno, G., García-Orenes, F., Mataix-Solera, J., Mataix-Beneyto, J., Bååth, E., 2011. Soil microbial recolonisation after a fire in a Mediterranean forest. Biology and Fertility of Soils 47, 261-272. doi:10.1007/s00374-010-0532-2

Caporaso, J.G., Kuczynski, J., Stombaugh, J., Bittinger, K., Bushman, F.D., Costello, E.K., Fierer, N., Pena, A.G., Goodrich, J.K., Gordon, J.I., Huttley, G.A., Kelley, S.T., Knights, D., Koenig, J.E., Ley, R.E., Lozupone, C.A., McDonald, D., Muegge, B.D., Pirrung, M., Reeder, J., Sevinsky, J.R., Turnbaugh, P.J., Walters, W.A., Widmann, J., Yatsunenko, T., Zaneveld, J., Knight, R., 2010a. QIIME allows analysis of high-throughput community sequencing data. Nature Methods 7 , 335-336. doi:10.1038/nmeth.f.303

Caporaso, J.G., Bittinger, K., Bushman, F.D., DeSantis, T.Z., Andersen, G.L., Knight, R., 2010b. PyNAST: a flexible tool for aligning sequences to a template alignment. Bioinformatics 26, 266-267. doi:10.1093/bioinformatics/btp636

Caporaso, J.G., Lauber, C.L., Walters, W.A., Berg-Lyons, D., Huntley, J., Fierer, N., Owens, S.M., Betley, J., Fraser, L., Bauer, M., Gormley, N., Gilbert, J.A., Smith, G., Knight, R., 2012. Ultra-high-throughput microbial community analysis on the Illumina HiSeq and MiSeq platforms. The ISME Journal 6, 1621-1624. doi:10.1038/ismej.2012.8

Castaño, C., Hernández-Rodríguez, M., Geml, J., Eberhart, J., Olaizola, J., Oria-deRueda, J.A., Martín-Pinto, P., 2020. Resistance of the soil fungal communities to medium-intensity fire prevention treatments in a Mediterranean scrubland. Forest Ecology and Management 472, 118217. doi:10.1016/j.foreco.2020.118217 
411 Certini, G., 2005. Effects of fire on properties of forest soils: a review. Oecologia 143, 1-10. doi:10.1007/s00442-004-1788-8

Certini, G., 2014. Fire as a soil-forming factor. Ambio 43, 191-195. doi:10.1007/s 13280-013-0418-2

Dooley, S.R., Treseder, K.K., 2012. The effect of fire on microbial biomass: a metaanalysis of field studies. Biogeochemistry 109, 49-61. doi:10.1007/s10533-0119633-8

Dove, N.C., Hart, S.C., 2017. Fire Reduces Fungal Species Richness and In Situ Mycorrhizal Colonization: A Meta-Analysis. Fire Ecology 13, 37-65. doi:10.4996/fireecology.130237746

Egidi, E., McMullan-Fisher, S., Morgan, J.W., May, T., Zeeman, B., Franks, A.E., 2016. Fire regime, not time-since-fire, affects soil fungal community diversity and composition in temperate grasslands. FEMS Microbiology Letters 363, fnw196. doi:10.1093/femsle/fnw196

Eivazi, F., Tabatabai, M.A., 1988. Glucosidases and galactosidases in soils. Soil Biology and Biochemistry 20,601-606. doi:10.1016/0038-0717(88)90141-1

Fernández-García, V., Miesel, J., Baeza, M.J., Marcos, E., Calvo, L., 2019. Wildfire effects on soil properties in fire-prone pine ecosystems: Indicators of burn severity legacy over the medium term after fire. Applied Soil Ecology 135, 147-156. doi:10.1016/j.apsoil.2018.12.002

Fontúrbel, M.T., Barreiro, A., Vega, J.A., Martín, A., Jiménez, E., Carballas, T., Fernández, C., Díaz-Raviña, M., 2012. Effects of an experimental fire and post-fire stabilization treatments on soil microbial communities. Geoderma 191, 51-60. doi:10.1016/j.geoderma.2012.01.037

Fritze, H., Pennanen, T., Pietikäinen, J., 1993. Recovery of soil microbial biomass and 

activity from prescribed burning. Canadian Journal of Forest Research 23, 12861290. doi:10.1139/x93-164

Gardes, M., Bruns, T.D., 1993. ITS primers with enhanced specificity for basidiomycetes, application to the identification of mycorrhizae and rusts. Molecular Ecology 2, 113-118. doi:10.1111/J.1365-294x.1993.Tb00005.X

Goberna, M., García, C., Insam, H., Hernández, M.T., Verdú, M., 2012. Burning fireprone Mediterranean shrublands: immediate changes in soil microbial community structure and ecosystem functions. Microbial Ecology 64, 242-255. doi:10.1007/s00248-011-9995-4

Goberna, M., García, C., Verdú, M., 2014. A role for biotic filtering in driving phylogenetic clustering in soil bacterial communities. Global Ecology and Biogeography 23, 1346-1355. doi:10.1111/geb.12227

Goberna, M., Verdú, M., 2018. Phylogenetic-scale disparities in the soil microbial diversity-ecosystem functioning relationship. The ISME Journal 12, 2152-2162. doi:10.1038/s41396-018-0162-5

Goberna, M., Verdú, M., 2016. Predicting microbial traits with phylogenies. The ISME Journal 10, 959-967. doi:10.1038/ismej.2015.171

Graham, E.B., Knelman, J.E., Schindlbacher, A., Siciliano, S., Breulmann, M., Yannarell, A., Beman, J.M., Abell, G., Philippot, L., Prosser, J., Foulquier, A., Yuste, J.C., Glanville, H.C., Jones, D.L., Angel, R., Salminen, J., Newton, R.J., Bürgmann, H., Ingram, L.J., Hamer, U., Siljanen, H.M.P., Peltoniemi, K., Potthast, K., Bañeras, L., Hartmann, M., Banerjee, S., Yu, R.Q., Nogaro, G., Richter, A., Koranda, M., Castle, S.C., Goberna, M., Song, B., Chatterjee, A., Nunes, O.C., Lopes, A.R., Cao, Y., Kaisermann, A., Hallin, S., Strickland, M.S., Garcia-Pausas, J., Barba, J., Kang, H., Isobe, K., Papaspyrou, S., Pastorelli, R., Lagomarsino, A., 
Lindström, E.S., Basiliko, N., Nemergut, D.R., 2016. Microbes as engines of ecosystem function: When does community structure enhance predictions of ecosystem processes? Frontiers in Microbiology 7. doi:10.3389/fmicb.2016.00214

Griffiths, B.S., Philippot, L., 2013. Insights into the resistance and resilience of the soil microbial community. FEMS Microbiology Reviews 37, 112-129. doi:10.1111/j.1574-6976.2012.00343.x

Hadfield, J.D., 2010. MCMC Methods for Multi-Response Generalized Linear Mixed Models: The MCMCglmm R Package. Journal of Statistical Software 33. doi:10.18637/jss.v033.i02

Hart, S.C., DeLuca, T.H., Newman, G.S., MacKenzie, M.D., Boyle, S.I., 2005. Post-fire vegetative dynamics as drivers of microbial community structure and function in forest soils. Forest Ecology and Management 220, 166-184. doi:10.1016/j.foreco.2005.08.012

Hernández, T., García, C., Reinhardt, I., 1997. Short-term effect of wildfire on the chemical, biochemical and microbiological properties of Mediterranean pine forest soils. Biology and Fertility of Soils 25, 109-116. doi:10.1007/s003740050289

Hoare, J.P., Laidler, K.J., 1950. The molecular kinetics of the urea-urease system. II. The inhibition by products. Journal of the American Chemical Society 72, 24872489. doi:10.1021/ja01162a037

Holden, S.R., Treseder, K.K., 2013. A meta-analysis of soil microbial biomass responses to forest disturbances. Frontiers in Microbiology 4. doi:10.3389/fmicb.2013.00163

Hooper, D.U., Johnson, L., 1999. Nitrogen limitation in dryland ecosystems: Responses to geographical and temporal variation in precipitation. Biogeochemistry 46, $247-$ 293. doi:10.1007/BF01007582 
Johnson, D.W., Curtis, P.S., 2001. Effects of forest management on soil C and N storage: meta analysis. Forest Ecology and Management 140, 227-238.

doi:10.1016/S0378-1127(00)00282-6

Kandeler, E., Gerber, H., 1988. Short-term assay of soil urease activity using colorimetric determination of ammonium. Biology and Fertility of Soils 6, 68-72. doi:10.1007/BF00257924

Keeley, J.E., Bond, W.J., Bradstock, R.A., Pausas, J.G., Rundel, P.W., 2012. Fire in Mediterranean ecosystems: ecology, evolution and management. Cambridge University Press, Cambridge, UK.

Kembel, S.W., Cowan, P.D., Helmus, M.R., Cornwell, W.K., Morlon, H., Ackerly, D.D., Blomberg, S.P., Webb, C.O., 2010. Picante: R tools for integrating phylogenies and ecology. Bioinformatics 26, 1463-1464.

doi:10.1093/bioinformatics/btq166

Kembel, S.W., Wu, M., Eisen, J.A., Green, J.L., 2012. Incorporating 16S gene copy number information improves estimates of microbial diversity and abundance. PLoS Computational Biology 8, e1002743. doi:10.1371/journal.pcbi.1002743

Knicker, H., 2007. How does fire affect the nature and stability of soil organic nitrogen and carbon? A review. Biogeochemistry 85, 91-118. doi:10.1007/s10533-0079104-4

Lavorel, S., 1999. Ecological diversity and resilience of Mediterranean vegetation to disturbance. Diversity and Distributions 5, 3-13. doi:10.1046/j.14724642.1999.00033.x

López-Poma, R., Bautista, S., 2014. Plant regeneration functional groups modulate the response to fire of soil enzyme activities in a Mediterranean shrubland. Soil Biology and Biochemistry 79, 5-13. doi:10.1016/j.soilbio.2014.08.016 
Martiny, J.B.H., Jones, S.E., Lennon, J.T., Martiny, A.C., 2015. Microbiomes in light of traits: A phylogenetic perspective. Science 350, aac9323. doi:10.1126/science.aac9323

Mataix-Solera, J., Guerrero, C., García-Orenes, F., Bárcenas, G.M., Pilar Torres, M., 2009. Forest fire effects on soil microbiology, in: Cerdá, A., Robichaud, P.R. (Eds.), Fire Effects on Soils and Restoration Strategies. Science Publishers, Enfield (NH), pp. 133-176. doi:10.1201/9781439843338-c5

Mikita-Barbato, R.A., Kelly, J.J., Tate, R.L., 2015. Wildfire effects on the properties and microbial community structure of organic horizon soils in the New Jersey Pinelands. Soil Biology and Biochemistry 86, 67-76. doi:10.1016/j.soilbio.2015.03.021

Moya, D., González-De Vega, S., García-Orenes, F., Morugán-Coronado, A., Arcenegui, V., Mataix-Solera, J., Lucas-Borja, M.E., De las Heras, J., 2018. Temporal characterisation of soil-plant natural recovery related to fire severity in burned Pinus halepensis Mill. forests. Science of the Total Environment 640-641, 42-51. doi:10.1016/j.scitotenv.2018.05.212

Moya, D., González-De Vega, S., Lozano, E., García-Orenes, F., Mataix-Solera, J., Lucas-Borja, M.E., de las Heras, J., 2019. The burn severity and plant recovery relationship affect the biological and chemical soil properties of Pinus halepensis Mill. stands in the short and mid-terms after wildfire. Journal of Environmental Management 235, 250-256. doi:10.1016/j.jenvman.2019.01.029

Muñoz-Rojas, M., Erickson, T.E., Martini, D., Dixon, K.W., Merritt, D.J., 2016. Soil physicochemical and microbiological indicators of short, medium and long term post-fire recovery in semi-arid ecosystems. Ecological Indicators 63, 14-22. doi:10.1016/j.ecolind.2015.11.038 
536 Nannipieri, P., Grego, S., Ceccanti, B., 1990. Ecological significance of the biological 537 activity in soil, in: Bollag, J.M., Stotzky, G. (Eds.), Soil Biochemistry. Marcel $538 \quad$ Dekker, New York, pp 293-355

539 Navarro-Cano, J.A., Verdú, M., García, C., Goberna, M., 2015. What nurse shrubs can 540 do for barren soils: rapid productivity shifts associated with a 40 years ontogenetic gradient. Plant and Soil 388, 197-209. doi:10.1007/s11104-014-2323-2

542

Pérez-Valera, E., Goberna, M., Verdú, M., 2019. Fire modulates ecosystem functioning through the phylogenetic structure of soil bacterial communities. Soil Biology and Biochemistry 129, 80-89. doi:10.1016/j.soilbio.2018.11.007

Pérez-Valera, E., Goberna, M., Verdú, M., 2015. Phylogenetic structure of soil bacterial communities predicts ecosystem functioning. FEMS Microbiology Ecology 91, fiv031. doi:10.1093/femsec/fiv031

Pérez-Valera, E., Verdú, M., Navarro-Cano, J.A., Goberna, M., 2018. Resilience to fire of phylogenetic diversity across biological domains. Molecular Ecology 27, 28962908. doi:10.1111/mec.14729

Pressler, Y., Moore, J.C., Cotrufo, M.F., 2019. Belowground community responses to fire: meta-analysis reveals contrasting responses of soil microorganisms and mesofauna. Oikos 128, 309-327. doi:10.1111/oik.05738

Quensen, J., 2020. QsRutils: R Functions Useful for Community Ecology. R package version 0.1.4. https://github.com/jfq3/QsRutils

R Core Team, 2019. R: A Language and Environment for Statistical Computing.

Rincón, A., Santamaría, B.P., Ocaña, L., Verdú, M., 2014. Structure and phylogenetic diversity of post-fire ectomycorrhizal communities of maritime pine. Mycorrhiza 24, 131-141. doi:10.1007/s00572-013-0520-0

Sáenz de Miera, L.E., Pinto, R., Gutierrez-Gonzalez, J.J., Calvo, L., Ansola, G., 2020. 
Wildfire effects on diversity and composition in soil bacterial communities. Science of The Total Environment 726, 138636. doi:10.1016/j.scitotenv.2020.138636

Shade, A., Peter, H., Allison, S.D., Baho, D.L., Berga, M., Bürgmann, H., Huber, D.H., Langenheder, S., Lennon, J.T., Martiny, J.B.H., Matulich, K.L., Schmidt, T.M., Handelsman, J., 2012. Fundamentals of microbial community resistance and resilience. Frontiers in Microbiology 3. doi:10.3389/fmicb.2012.00417

Stamatakis, A., 2014. RAxML version 8: a tool for phylogenetic analysis and postanalysis of large phylogenies. Bioinformatics 30, 1312-1313. doi:10.1093/bioinformatics/btu033

Stetter, K.O., 1999. Extremophiles and their adaptation to hot environments. FEBS Letters 452, 22-25. doi:10.1016/S0014-5793(99)00663-8

Stone, G.N., Nee, S., Felsenstein, J., 2011. Controlling for non-independence in comparative analysis of patterns across populations within species. Philosophical Transactions of the Royal Society of London. Series B, Biological Sciences 366, 1410-1424. doi:10.1098/rstb.2010.0311

Tabatabai, M.A., Bremner, J.M., 1969. Use of $p$-nitrophenyl phosphate for assay of soil phosphatase activity. Soil Biology and Biochemistry 1, 301-307. doi:10.1016/0038-0717(69)90012-1

Uribe, C., Inclán, R., Sánchez, D.M., Clavero, M.A., Fernández, A.M., Morante, R., Cardeña, A., Blanco, A., Van Miegroet, H., 2013. Effect of wildfires on soil respiration in three typical Mediterranean forest ecosystems in Madrid, Spain. Plant and Soil 369, 403-420. doi:10.1007/s11104-012-1576-x

White, T., Bruns, T., Lee, S., Taylor, J., 1990. Amplification and direct sequencing of fungal ribosomal RNA genes for phylogenetics, in: Innis, M.A., Gelfand, D.H., 

Applications. Academic Press, Inc., New York, pp. 315-322.

588 Xue, L., Li, Q., Chen, H., 2014. Effects of a wildfire on selected physical, chemical and 589 biochemical soil properties in a Pinus massoniana forest in south China. Forests 5,

590 2947-2966. doi:10.3390/f5122947

591 
592 Table 1. Statistical analysis showing: a) Short-term (0-3 years) fire effects on microbial

593 EFs based on paired t-tests comparing burned and unburned transects; b) Effect of time

594 since fire on microbial EFs measured as the paired difference $(\Delta)$ between burned and

595 unburned transects; Bayesian post-mean estimates and their 95\% expected credible

596 intervals (in brackets) are shown. Significant differences are shown in bold type. ${ }^{*} p<$

$597 \quad 0.001$

\begin{tabular}{lcc}
\hline Microbial EFs & a) Short-term fire effects $\left(\mathrm{t}_{14}\right)$ & b) Effect of time since fire \\
\hline Max. $\mathrm{CO}_{2}$-C production & $\mathbf{- 4 . 3 6} *$ & $\mathbf{2 . 1 4}[\mathbf{0 . 6 9 , 3 . 7 2}]$ \\
$\beta$-glucosidase activity & $\mathbf{- 9 . 4 0 *}$ & $\mathbf{0 . 0 0 9}[\mathbf{0 . 0 0 6 , 0 . 0 1 4}]$ \\
Phosphatase activity & $\mathbf{- 6 . 2 3} *$ & $\mathbf{0 . 0 1 7}[\mathbf{0 . 0 0 6 , 0 . 0 2 8}]$ \\
Urease activity & 1.15 & $0.005[-0.0002,0.010]$
\end{tabular}

598 
Table 2. Results of two Generalized Linear Mixed Models showing Bayesian post-mean estimates and their 95\% expected credible intervals (in brackets) of the effect of i) physical and chemical soil parameters and ii) fungal and bacterial phylogenetic diversity (stdMPD) on C mineralization potential (Max. $\mathrm{CO}_{2}-\mathrm{C}$ production) and enzymatic activities. Dependent and independent variables were measured as the paired difference $(\Delta)$ between burned and unburned transects. Significant differences (i.e. credible intervals not including zero) are shown in bold type.

\begin{tabular}{|c|c|c|c|c|}
\hline Predictor & Max. $\mathrm{CO}_{2}-\mathrm{C}$ production & $\beta$-glucosidase activity & Phosphatase activity & Urease activity \\
\hline Total Organic C & $-0.02[-0.05,0.01]$ & $-0.09[-0.2,0.04]$ & $-0.07[-0.4,0.24]$ & $-0.31[-0.5,-0.13]$ \\
\hline Total Nitrogen & $0.59[0.1,1.14]$ & $3.37[0.67,5.83]$ & $8.3[2.7,13.5]$ & $9.17[5.84,12.6]$ \\
\hline Humidity & $-0.02[-0.044,0.0004]$ & $0.05[-0.05,0.15]$ & $0.21[-0.02,0.47]$ & $-0.14[-0.29,-0.004]$ \\
\hline Electrical Conductivity & $0.002[0.0005,0.004]$ & $0.004[-0.004,0.01]$ & $0.001[-0.02,0.02]$ & $-0.01[-0.01,0.003]$ \\
\hline $\mathrm{NO}_{3}{ }^{-}-\mathrm{N}$ & $-0.002[-0.004,-0.001]$ & $-0.01[-0.02,-0.002]$ & $-0.01[-0.02,0.01]$ & $0.01[-0.005,0.02]$ \\
\hline $\mathrm{NH}_{4}{ }^{+}-\mathrm{N}$ & $-0.005[-0.014,0.005]$ & $-0.01[-0.05,0.04]$ & $0.06[-0.04,0.15]$ & $0.02[-0.04,0.08]$ \\
\hline
\end{tabular}


604 Fig. 1. Post-fire trends of maximum degree of microbial $\mathrm{CO}_{2}-\mathrm{C}$ production, $\beta$ 605 glucosidase activity, alkaline phosphatase activity and urease activity. Filled circles 606 indicate burned transects and unfilled circles unburned transects. Shaded and hatched 607 areas show the confidence intervals of linear regressions between burned and unburned 608 transects, respectively. Asterisks indicate the existence of a significant post-fire 609 temporal trend of the studied parameter measured as the paired difference $(\Delta)$ between 610 burned and unburned transects $(p<0.05)$. Data are expressed on a dry weight basis.

611

612 Fig. 2. Biplot of the first and second axes obtained from a principal component analysis 613 that included the paired difference $(\Delta)$ between burned and unburned transects of $i$ ) 614 main soil abiotic properties (blue arrows; GH gravimetric humidity; TOC total organic 615 carbon; TN total nitrogen; EC electrical conductivity; $\mathrm{pH} ; \mathrm{NO}_{3}{ }^{-}-\mathrm{N}$ nitrate- $\mathrm{N} ; \mathrm{NH}_{4}{ }^{+}-\mathrm{N}$ ammonium- $N$ ), ii) EFs (purple arrows; $\max \mathrm{CO}_{2}-\mathrm{C}$ production; GA $\beta$-glucosidase

617 activity; PA phosphatase activity; UA urease activity) and iii) fungal (dark grey arrows) 618 and bacterial abundances (light grey arrows) at the phylum level. Arrows indicate the 619 factor loadings on each axis. Transects are coloured according to time since fire (in 620 months). 


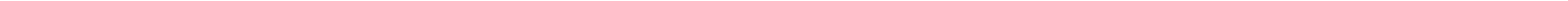




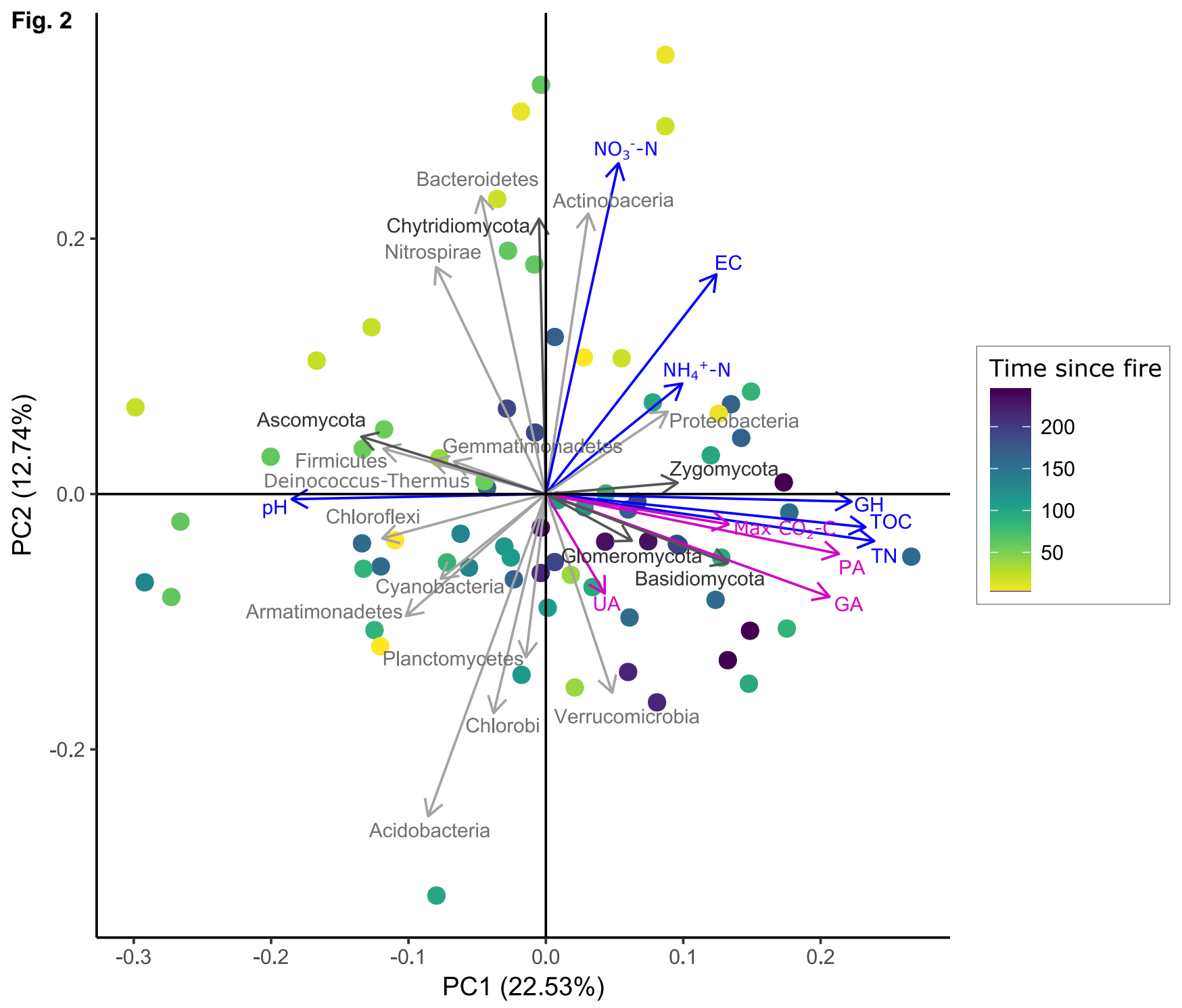

